\title{
APLIKASI SISTEM PENDATAAN BARANG HABIS PAKAI GUNA MENINGKATKAN KUALITAS STOK BARANG PADA PT. ANGKASA PURA II TANGERANG
}

\author{
Ruli Supriati ${ }^{1}$, Astri Wulan Sari ${ }^{2}$ \\ Universitas Raharja: Jalan Jend. Sudirman No. 40 Tangerang, Indonesia \\ e-mail: $\underline{\text { ruli@raharja.info }}^{1}$, astri.wulan@raharja.info ${ }^{2}$
}

\begin{abstract}
The warehouse is one of the places used to store the company's goods (assets). In general, the process of collecting used goods in carrying out activities of recording of expired goods in PT Angkasa Pura II Soekarno - Hatta Airport is still semi computerized that is using the manual form and Microsoft Excel software. The trouble encountered in conducting this research is matters occurring in collecting used goods that is numberization of Goods Received Goods Receipts (BAPBBP). This study aims to design the system of recording of goods used in PT Angkasa Pura II. The analytical method used is SWOT to analyze the problems of internal and external company. this method is also used to perform analysis of running procedures and systems, related to data collection of consumables and auctions. The design method uses UML (Unified Modeling Language). It is expected to develop information that can be used to manage the data of used goods and inventory quantities well that can produce information accurately, quickly, and appropriately for warehouse management in PT. Angkasa Pura II in the future.
\end{abstract}

Keywords: systems, data collection, warehouse

\section{PENDAHULUAN}

\section{Latar Belakang}

Gudang merupakan tempat yang penting karena di sana terletak berbagai macam barang milik perusahaan yang memiliki nilai jual. Perusahaan biasanya menugaskan satu atau lebih admin yaitu staff warehouse yang bertugas untuk melakukan berbagai macam proses kegiatan administrasi gudang meliputi kegiatan pencatatan dan pendataan yang berkaitan dengan pengelolaan data di dalam gudang, seperti barang yang masuk dan keluar, sisa persediaan barang pada gudang dan mencatat permintaan barang dari luar yaitu dari unit Satuan Teknik (ST). Administrasi gudang harus lebih bertanggung jawab dalam melaksanakan tugasnya, karena harus bertanggung jawab terhadap laporan barang yang tersedia di dalam gudang baik barang yang baru ataupun barang yang bekas untuk di sampaikan kepada Inventory \& Warehouse Management Manager dengan kesesuaian data inventory barang yang tersedia di gudang. 
PT Angkasa Pura II (Persero) adalah Badan Usaha Milik Negara (BUMN) yang bergerak di bidang pengelolaan dan pengusahaan bandar udara di Indonesia, bersama dengan PT Angkasa Pura I yang menitik beratkan pelayanan pada wilayah Indonesia bagian barat. Angkasa Pura II berkantor pusat di Bandara Internasional Soekarno-Hatta di Tangerang, Banten. PT Angkasa Pura II mengelola semua keperluan Bandara Soekarno - Hatta, termasuk dalam mengelola barang habis pakai seperti kursi, stroller, meja kerja dan lain-lain yang terdapat di semua Terminal dan di unit perkantoran Angkasa Pura II.

Proses pendataan dalam kegiatan pencatatan barang - barang yang telah habis masa pakai masih bersifat semi komputerisasi yaitu menggunakan form manual Berita Acara Penerimaan Barang Bekas Pakai (BAPBBP) dan menggunakan Microsoft Excel. Masalah yang sering terjadi yaitu penomoran dalam form BAPBBP sering terjadi kesalahan seperti pengulangan data (redudansi) dalam penomoran BAPBBP dan nomor yang terkadang tidak berurut. Hal tersebut dikarenakan penginputan data masih menggunakan Microsoft Excel, sehingga belum ada sebuah sistem yang bisa digunakan untuk mengelola data barang habis pakai dengan baik unuk dapat memperoleh informasi secara akurat, cepat, tepat dan informatif untuk keperluan di kemudian hari yaiu informasi jumlah barang bekas yang tersimpan di gudang.

Berdasarkan latar belakang masalah di atas maka dapat dijabarkan beberapa rumusan masalah yang terdapat di warehouse PT Angkasa Pura II sebagai berikut:

1. Bagaimana cara mempermudah admin warehouse dalam melakukan proses pendataan dan pengelolaan data barang habis pakai pada PT Angkasa Pura II Tangerang?

2. Bagaimana rancangan proses sistem untuk dapat mempermudah admin warehouse dalam melakukan pengolahan data yaitu klasifikasi barang habis pakai agar dapat menghasilkan suatu laporan yang akurat kepada warehouse and inventory management?

3. Bagaimana membuat sebuah sistem informasi yang dibutuhkan oleh PT Angkasa Pura II Tangerang dalam proses kegiatan pendataan dan pengolahan barang bekas pakai? 


\section{Literature Review}

1) Berdasarkan penelitian karya ilmiah yang telah dilakukan oleh Joko Dewanto dan Yetti Kusmira pada tahun 2014 dengan judul Analisis dan Perancangan Sistem Informasi Pengolahan Data Barang Masuk dan Keluar Gudang Barang Jadi dan Logistik di PT SNFOOD. Pada penelitian ini penulis mencoba menyelesaikan suatu permasalahan yang dihadapi yaitu sistem yang berjalan masih bersifat semi komputerisasi yaitu masih menggunakan Ms. Excel mulai dari penerimaan dan pengeluaran barang. Hal yang telah disampaikan oleh penulis bahwa ini kurang efisien dan data yang harus diolah dalam setiap harinya cukup banyak. Solusi dalam permasalahan tersebut adalah PT SNFOOD memerlukan suatu sistem informasi pengolahan data barang masuk dan barang keluar untuk mempermudah dalam proses pencarian data, pencatatan transaksi dan pengolahan stock. Aplikasi initerintegrasi dalam database maka dapatmempermudah pihak pengelola di bagian logistik mengetahui informasi barang.

2) Berdasarkan penelitian yang telah dilakukan oleh Dewi Sawitri pada tahun 2011 dengan judul Perancangan Sistem Informasi Manajemen Persediaan Barang "Electrolux Authorized Service CV Momentum Teknik". Pada penelitian ini dijelaskan permasalahan yang dihadapi yaitu permasalahan pada sistem inventory yang dimiliki yang menggunakanpendokumentasian data barang masuk dan barang keluar secara manual sehinggamembuat lambatnya kinerja perusahaan. Data-data tersebut tidak terintegrasi dantidak terkonsolidasi. Karena itu dibuat perancangan sistem informasi manajemenpersediaan barang secara komputerisasi dan terintegrasi agar mempercepat kinerja perusahaan. Penelitian ini menggunakan metode System Development Life Cycle (SDLC) mulai dari perencanaan sistem hinggatahap perancangan sistem yang rinci, mencakup perancangan database, perancangan kontrol, perancangan input output, hingga teknologinya. Dari penelitian tersebut dapat ditarik suatu kesimpulan yaitu dari laporan persediaan barang dapat diketahui macam-macam barang yangtermasuk ke dalam kategori barang-barang yang cepat terjual dan juga kinerjadari perusahaan jasa tersebut serta sistem kerjanya. Pemodelan 
sistem yang terkomputerisasi dan terintegrasi sehingga setiapdivisi terkait bisa mendapatkan informasi persediaan barang yang tersajisecara cepat dan tepat tanpa membutuhkan tanya jawab terlebih dahulukepada divisi-divisi terkait.

3) Berdasarkan penelitian yang telah dilakukan oleh Mhd Bustanur Rahmad dan Tedy Setiadi pada tahun 2011 dengan judul Perancangan Sistem Informasi Inventory Spare Part Elektronik Berbasis Web PHP (Studi CV Human Global Service daftarYoyakarta). Pada penelitian ini dijelaskan permasalahan yang dihadapi yaitu pencatatan barang dilakukan dengan cara manual yaitu untuk mengetahui data stok barangserta pembuatan laporannya dengan cara melakukan penulisan di buku. Olehsebab itu banyak waktu yang dibutuhkan untuk melakukan proses dalam menghasilkan laporan yang tepat dan transaksi penjualan barang yang akurat bagi pemilik dan mengurangi kesalahan dalam pencatatan. Berdasarkan permasalahan tersebut, maka dibutuhkan aplikasi dalam pengolahan data persediaan barang khususnya persediaan spare part serta laporan yang terkomputerisasi agar pencatatan arus barang masuk dan keluar dapat secara cepat, tepat dan akurat. Kesimpulannya, Aplikasi berupa sistem informasi inventory spare part elektronik yang dapat dijadikan sebagai alat bantu informasi untuk pengolahan data barang serta stok gudang danmencatat penggunaan biaya inventory. Melalui sistem informasi inventory ini, pihak manajemen dapat mengambilkeputusan berdasarkan rekapitulasi transaksi, sisa stok dan informasi lain.

4) Based on research that has been done by Lawrence Imeokparia in 2013 with the title Inventory Management System and Performance of Food and Beverages Companies in Nigeria.This study explores the relationship between inventory management and control andperformance and Food and Beverages companies in Nigeria. The results show that there significant relationship between inventory management and control and the performance of Food and Beverages companies in Nigeria. Inventory Control System is the process of managing inventory in order to meet customer demand at the lowest possible cost and with a minimum of investment. This research work employs the use of secondary data which 
provides repository records and accounts in a workable format. (berdasarkan penelitian yang dilakukan oleh Lawrence Imeokperia pada tahun 2013 yang berjudul Inventory Management System and Performance of Food and Beverages Companies in Negeria. Penelitian ini menjelaskan hubungan antara manajemen persediaan, kontrol, kinerja dan perusahaan Makanan dan Minuman di Nigeria. Hasilnya menunjukkan bahwa ada hubungan yang signifikan antara manajemen persediaan, kontrol, dan kinerja perusahaan Makanan dan Minuman di Nigeria. Sistem Pengendalian Persediaan adalah proses mengelola persediaan untuk memenuhi permintaan pelanggan dengan biaya serendah mungkin dan dengan investasi minimum. Penelitian ini bekerja menggunakan data sekunder yang menyediakan catatan dan catatan gudang dalam format yang bisa diterapkan.)

5) Based on research that has been done by Phindile Ndlala and Charles Mbohwa in 2017 with the title The Application Inventory Control Systems in Warehouse. Companies are making efforts on inventory control enhancement in order to deliver products and services to their customers rapidly at low cost. Better inventory control means effective operations of a firm resulting in cost reduction and ultimately increasing on profit. The purpose of this paper is to showcase the significance of proper inventory control systems application in warehouses. The inventory control techniques applicable in the warehouse such as batch quantities, ordering methods and inventory classification and as well as the factors contributing to poor inventory control. Re-order point (ROP) tracks the amount of stock that is left each time a withdrawal is made to decide whether to order or not to order. ROP determines the level where the action is needed to be taken to replenish the stock item. The paper reveals that employing inventory control comes with a big price. There are many problems that an organization needs to attend to. It is evident that ineffective inventory control is the main problem. In many cases the ROP is always related to the extent of working capital available. That means companies in developing countries tend to order a massive quantity of stock subject to the amount of working capital available. (Berdasarkan penelitian yang telah dilakukan oleh Phindile 
Ndlala dan Charles Mbohwa pada tahun 2017 dengan judul The Application Inventory Control Systems in Warehouse. Perusahaan melakukan upaya peningkatan kontrol inventaris untuk menghasilkan produk dan layanan kepada pelanggan mereka dengan cepat dengan biaya rendah. Kontrol inventaris yang lebih baik berarti operasi yang efektif dari perusahaan yang menghasilkan pengurangan biaya dan pada akhirnya meningkatkan laba. Tujuan dari penelitian ini adalah untuk menunjukkan pentingnya aplikasi sistem pengendalian persediaan yang tepat di gudang. Teknik pengendalian persediaan yang berlaku di gudang seperti jumlah batch, metode pemesanan dan klasifikasi inventaris dan serta faktor-faktor yang berkontribusi terhadap kontrol inventaris yang buruk. Re-order point (ROP) melacak jumlah stok yang tersisa setiap kali penarikan dilakukan untuk memutuskan apakah akan memesan atau tidak memesan. ROP menentukan tingkat dimana tindakan diperlukan untuk mengisi kembali stok barang. Penelitian ini mengungkapkan bahwa menggunakan kontrol persediaan datang dengan harga besar. Ada banyak masalah yang perlu diperhatikan oleh suatu organisasi. Jelas bahwa pengendalian persediaan yang tidak efektif adalah masalah utama. Dalam banyak kasus, ROP selalu terkait dengan sejauh mana modal kerja tersedia. Itu berarti perusahaan di negara berkembang cenderung memesan sejumlah besar stok tergantung pada jumlah modal kerja yang tersedia).

\section{METODE PENELITIAN}

\section{Metode Pengumpulan Data}

Sebagai bahan untuk menunjang materi laporan penelitian ini, maka digunakan beberapa metode penelitian yang dapat membantu dalam mendapatkan data dan informasi yang dibutuhkan. Metode pengumpulan data yang digunakan, antara lain :

\section{Metode Observasi}

Pengumpulan data dengan cara mengamati secara langsung prosedur yang berjalan pada unit warehouse, mempelajari urutan dokumen barang bekas pakai mulai dari penerimaan barang bekas sampai menjadi suatu laporan selain itu peneliti melakukan pencatatan secara sistematis terhadap 
objek yang diteliti. Observasi dilakukan di PT Angkasa Pura II (Persero) Cabang Utama Bandara Internasional Soekarno - Hatta Tangerang dimulai pada saat melakukan analisa Kuliah Kerja Praktek yaitu pada tanggal 25 September sampai dengan 31 Oktober 2017. Namun peneliti tetap melakukan observasi bertujuan untuk memenuhi kelengkapan data pada bulan April sampai dengan bulan Juni 2018.

\section{a. Metode Wawancara}

Melakukan kegiatan tanya jawab dan diskusi mengenai informasi yang diperlukan dalam proses penelitian. Wawancara dilakukan kepada Bapak Dedy Carsito dan Ibu Margaret yang menjabat sebagai staff warehouse. Bertanya mengenai sistem yang sedang berjalan saat ini dan apa saja kendala-kendala yang dihadapi terutama dalam hal pendataan dan pengelolaan barang-barang bekas.

\section{b. Metode Studi Pustaka}

Mempelajari, mengumpulkan, dan meringkas ulang jurnal, paper, skripsi, laporan tugas akhir, laporan kuliah kerja praktek, serta bahan referensi yang terkait dengan penyusunan laporan Tugas Akhir (TA) untuk mendapatkan data dan informasi yang diperlukan.

\section{Metode Analisa}

Setelah tahap dilakukannya pengumpulan data dalam penelitian kemudian data diolah dan dianalisis. Peneliti menggunakan metode analisis SWOT dalam melakukan penelitian dengan berdasarkan kepada logika untuk memaksimalkan kekuatan (strengths), kelemahan (weaknesses), peluang (opportunities), dan ancaman (threats) terhadap PT Angkasa Pura II. Tujuan menggunakan analisa SWOT adalah untuk mengetahui permasalahan yang sedang dihadapi, bagaimana solusi dari permasalahan yang ada dan membantu Inventory Warehouse Management Manager dalam mengambil keputusan.

\section{Metode Perancangan}

Penelitian ini menggunakan metode rancangan model yang berorientasi objek dengan menggunakan diagram UML (Unified Modeling Language) yaitu terdapat Use Case Diagram, Sequence Diagram, Activity Diagram, Class Diagram. 


\section{Metode Pengujian}

Proses pengujian sistem informasi pendataan barang habis pakai pada PT Angkasa Pura II berbasis WEB ini peneliti menggunakan Metode Blackbox Testing untuk dapat diketahui apakah sistem yang telah dibuat sesuai dengan kebutuhan fungsional (user requirement) atau tidak dari keinginan stakeholder. Blackbox Testing digunakan untuk melakukan uji coba dalam memfokuskan keperluan fungsional software. Pengujian blackbox dilakukan sebagai usaha dalam menemukan fungsi belum tepat atau fungsi yang hilang, kesalahan sistem, kesalahan akses atau koneksi dengan database eksternal, kesalahan kinerja.

\section{HASIL DAN PEMBAHASAN}

\section{Perancangan Sistem}

1. Usecase Diagram Sistem yang diusulkan

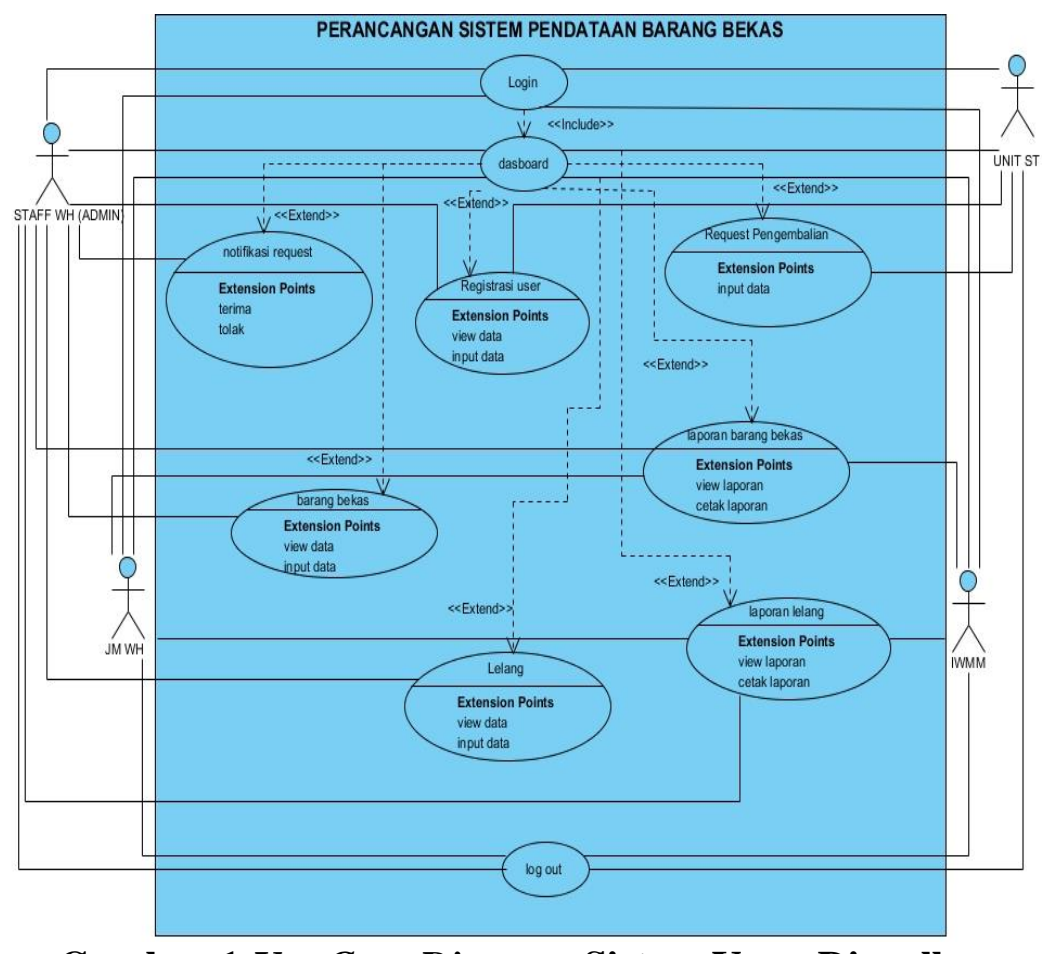

Gambar 1 Use Case Diagram Sistem Yang Diusulkan 
2. Activity Diagram requestpengembalian barang bekas yang Diusulkan

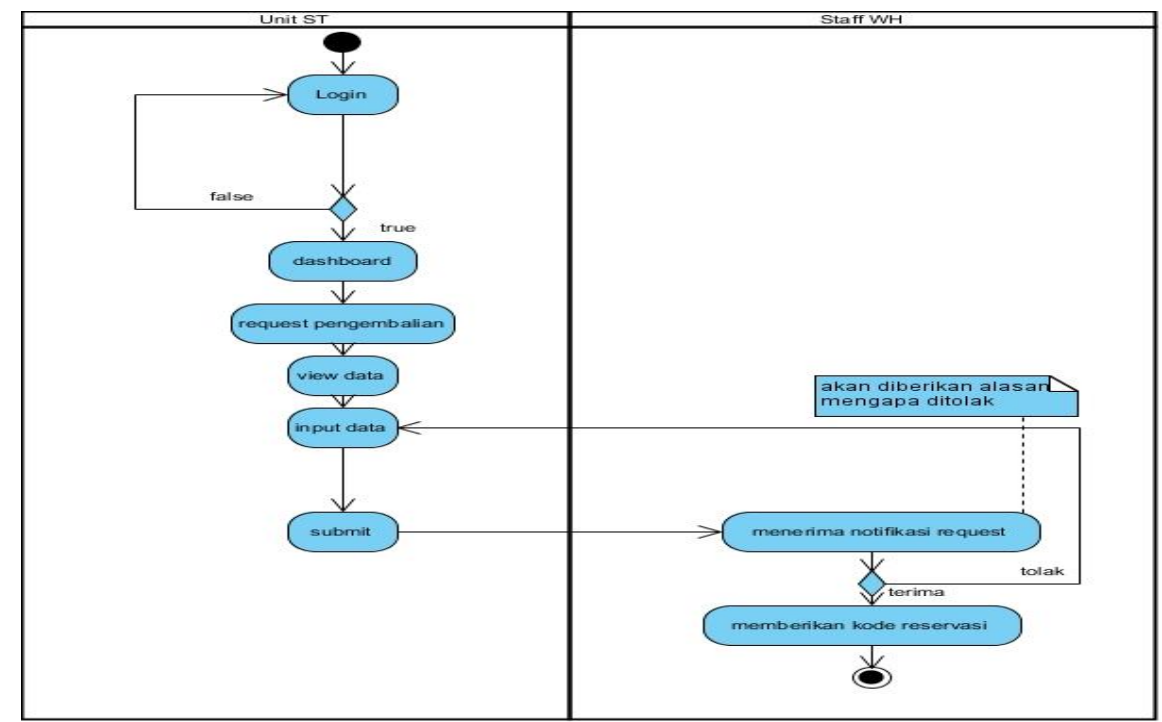

Gambar 2 activity diagram request pengembalian barang bekas

3. Sequence diagram request pengembalian barang bekas yang diusulkan

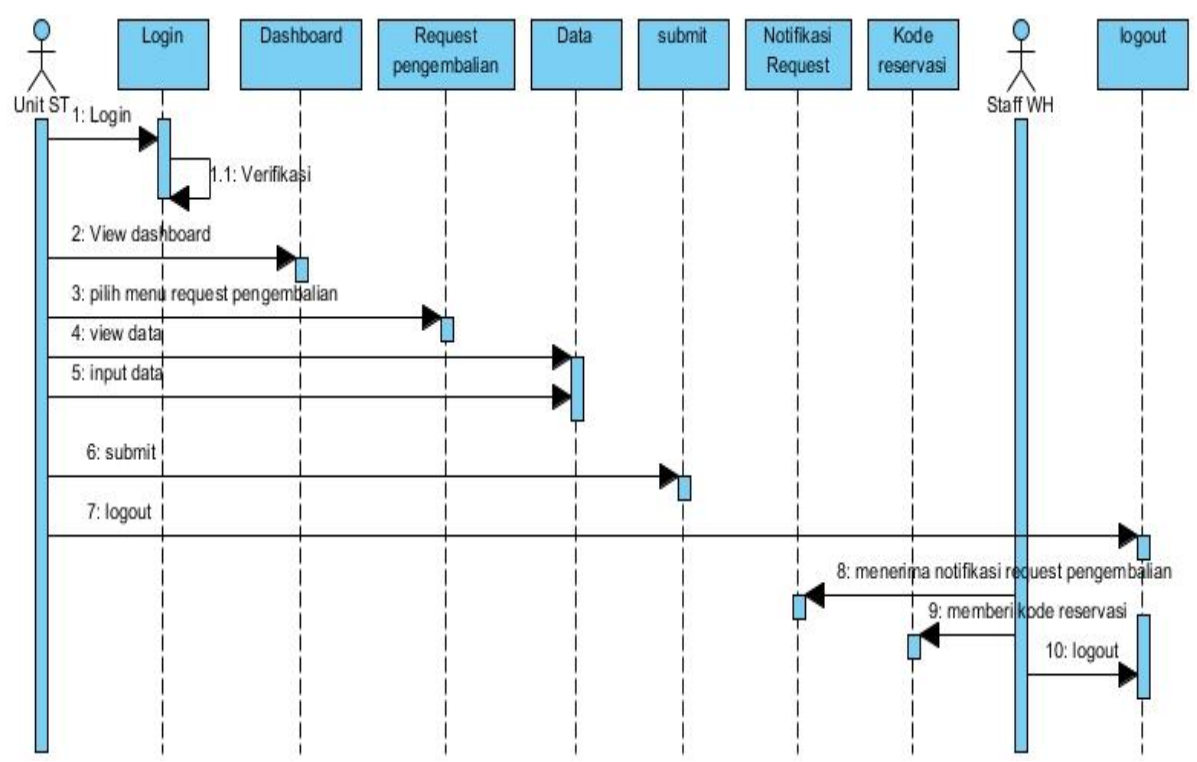

Gambar 3 sequence diagram request pengembalian barang bekas 
4. Class Diagram yang Diusulkan
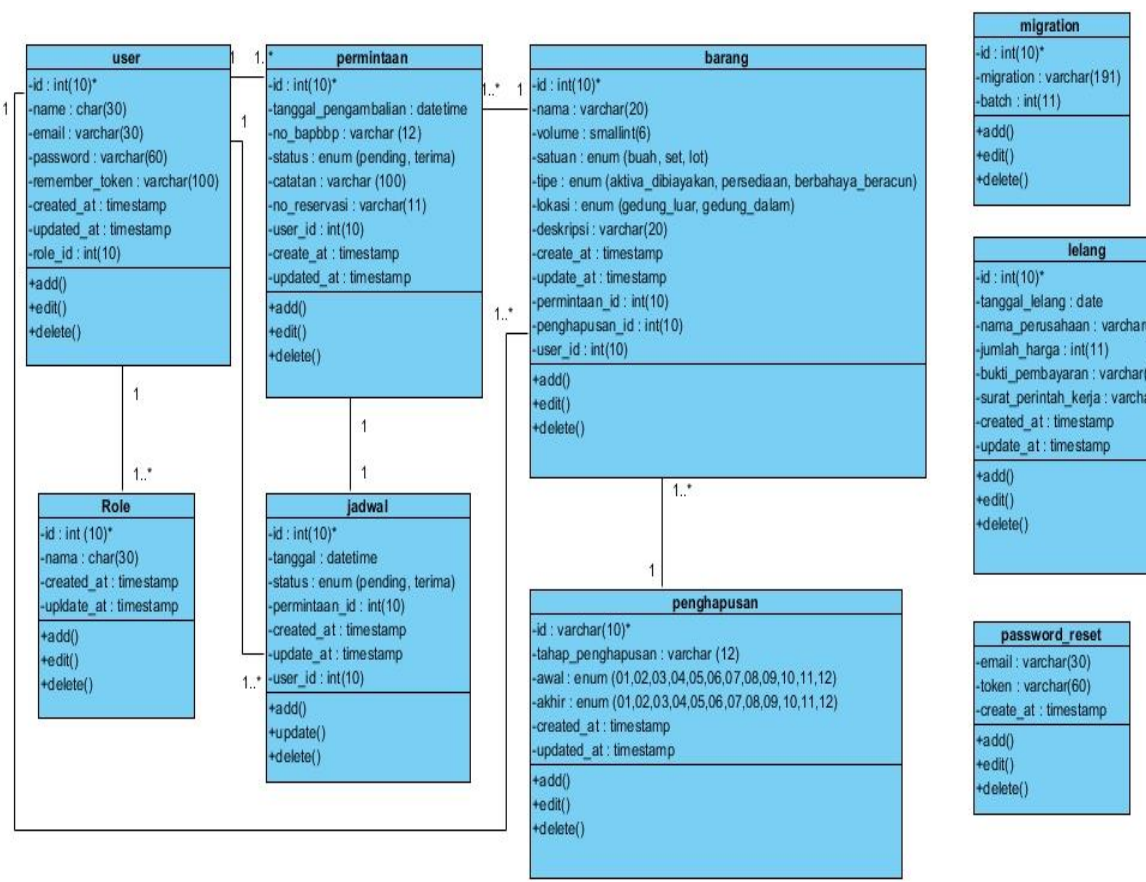

Gambar 4 Class Diagram yang diusulkan
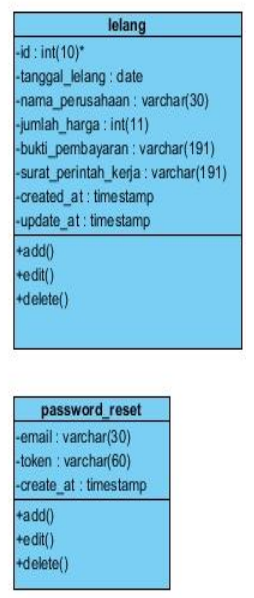

\section{Rancangan Program}

Berikut ini merupakan rancangan program pendataan barang habis pakai :

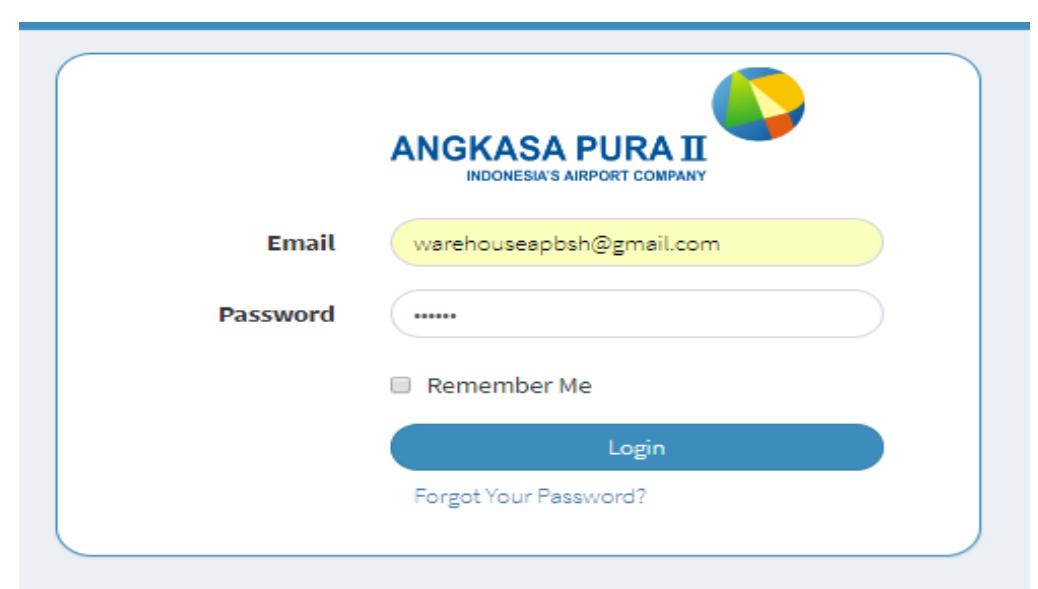

Gambar 5 Tampilan Menu Login 


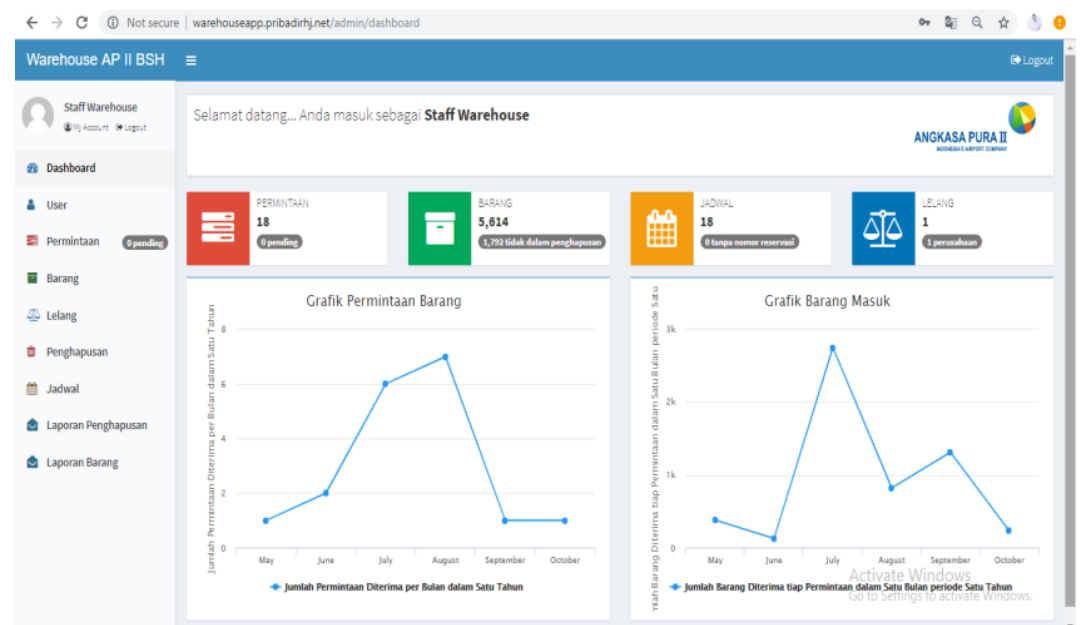

Gambar 6 Tampilan Dashboard

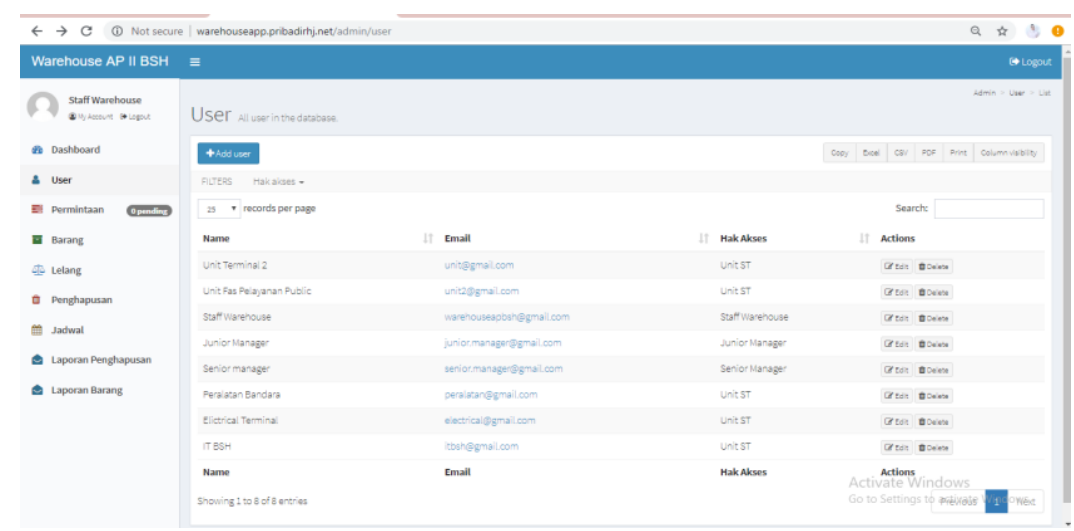

Gambar 7 Tampilan Menu User

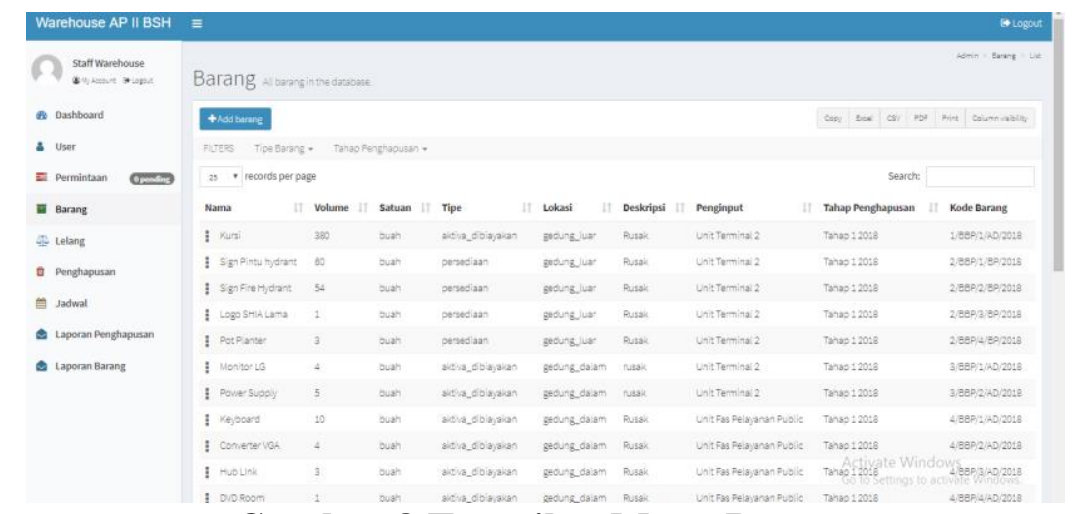

Gambar 8 Tampilan Menu Barang 


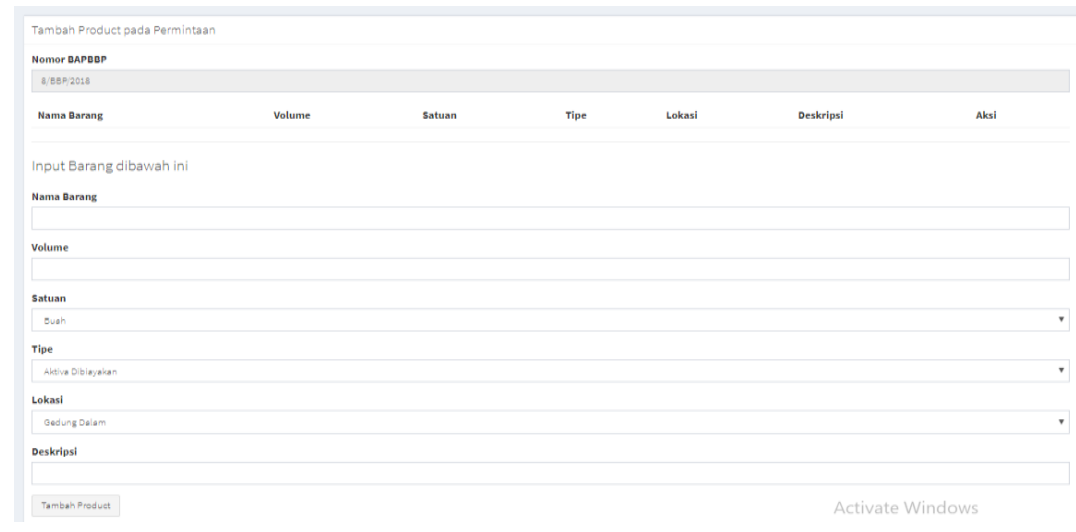

Gambar 9 Tampilan Form Input Permintaan

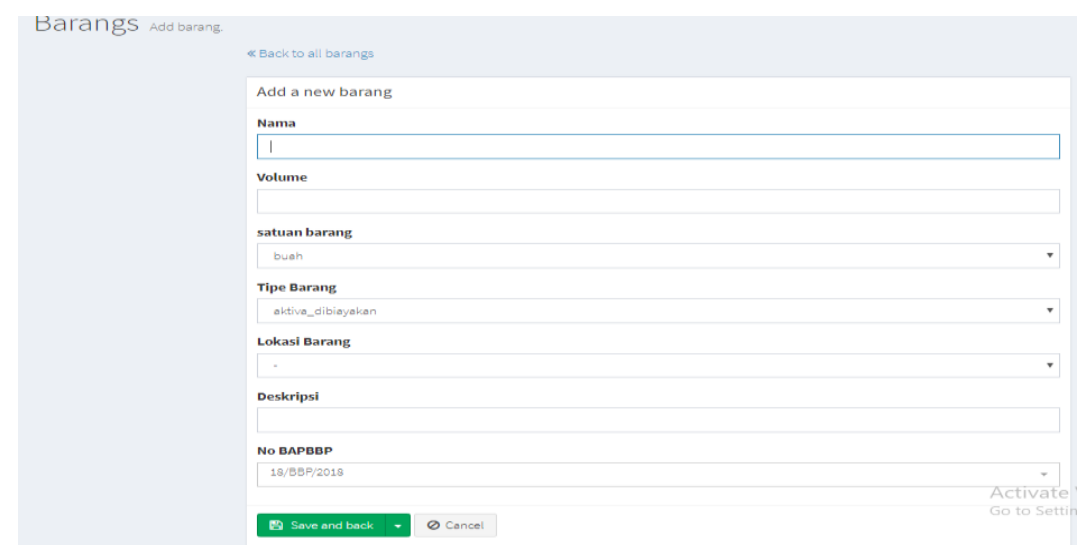

Gambar 10 Tampilan Form Barang Bekas

\begin{tabular}{l} 
Add a new penghapusan \\
Tahap Penghapusan \\
Tahap 12018 \\
Awal Bulan Lelang \\
\hline Juli \\
Akhir Bulan Lelang \\
\hline Oktober \\
\hline D Save and back \\
\hline
\end{tabular}

Gambar 11 Tampilan Form Penghapusan 


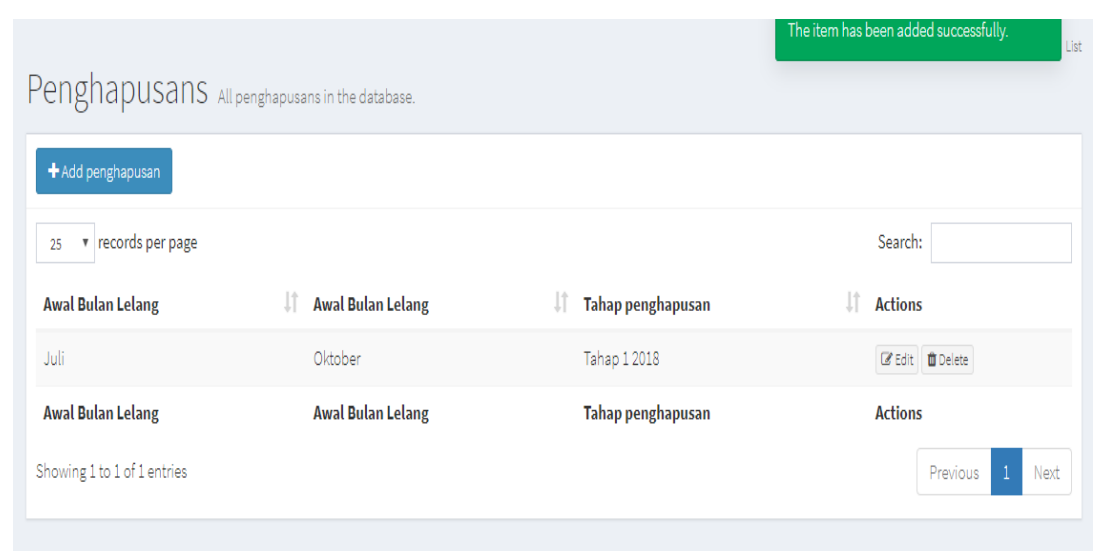

Gambar 12 Tampilan Hasil Input Data Penghapusan

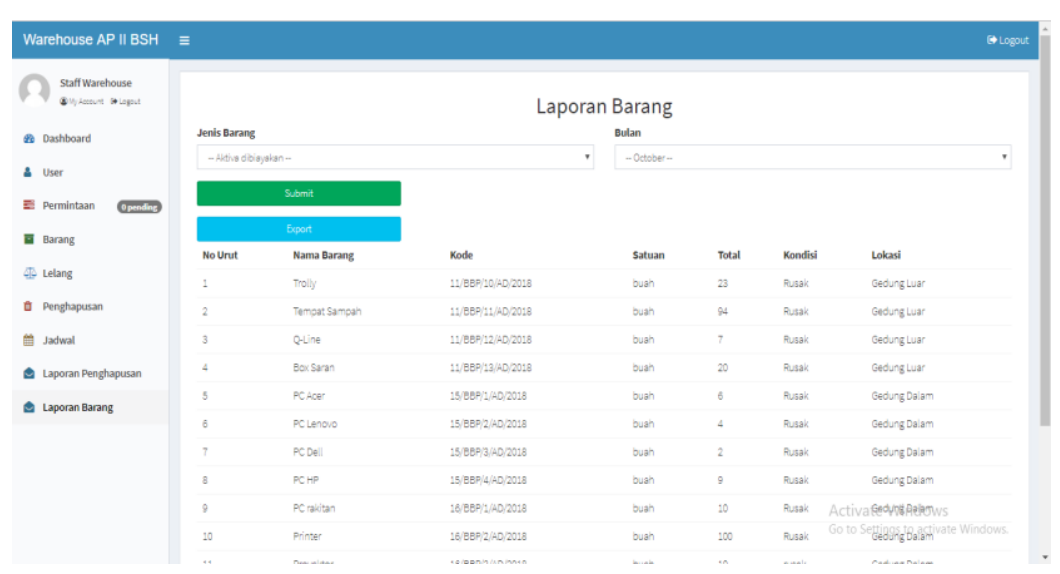

Gambar 13 Tampilan Laporan Barang Bekas

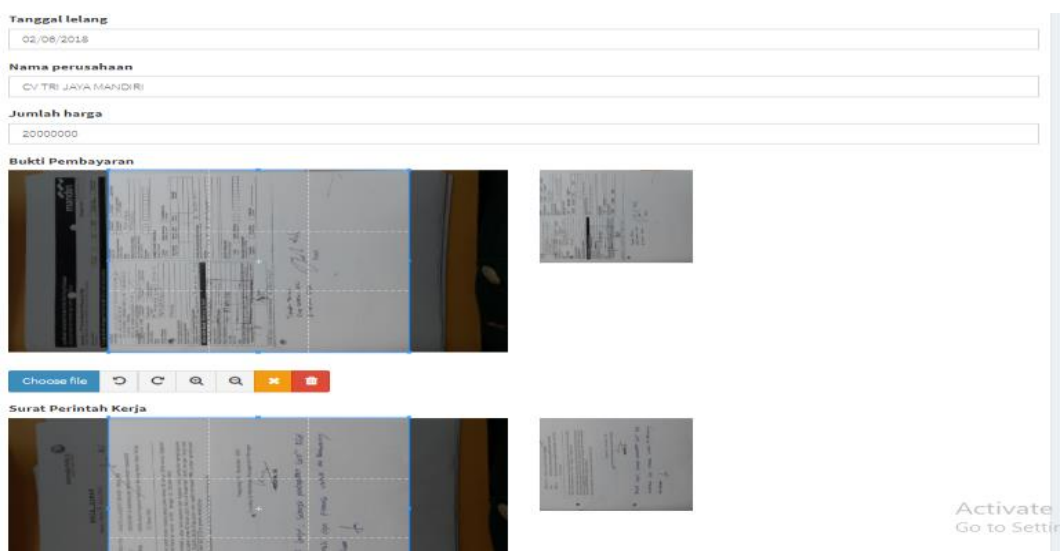

Gambar 14 Tampilan Form Lelang 


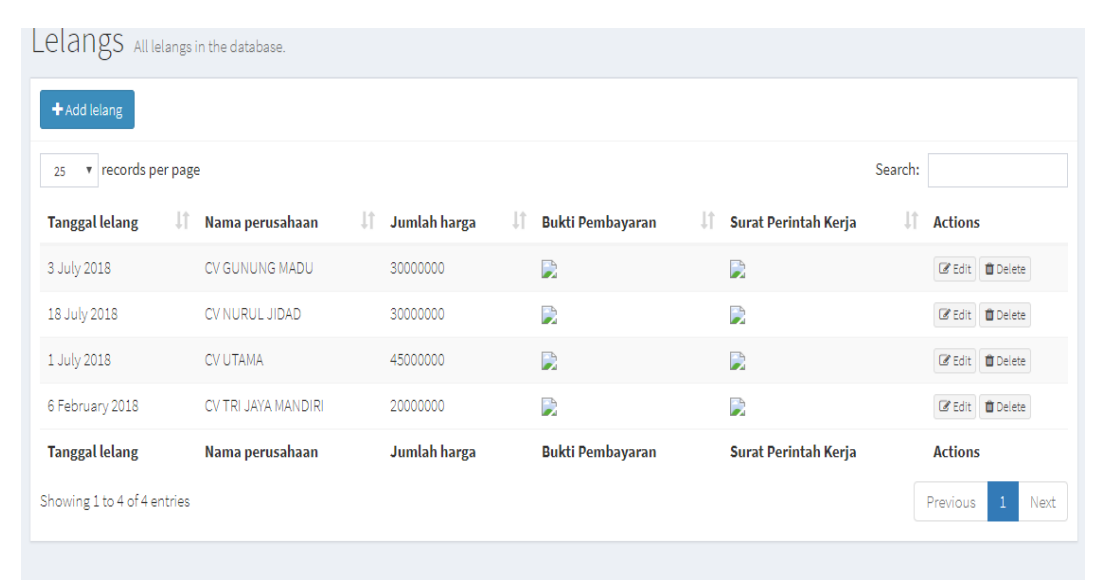

\section{Gambar 15 Tampilan Hasil Tambah Data Lelang}

\section{KESIMPULAN}

1. Peneliti melakukan penelitian untuk mempermudah admin (Staff Warehouse) dalam melakukan pendataan dan pengelolaan data barang habis pakai dan penyimpanan data lelang pada PT Angkasa Pura II yaitu dengan merancang, membuat serta mengimplementasikan sistem yang dapat digunakan untuk melakukan pendataan barang bekas dan pengolahan data oleh Staff Warehouse kemudian dapat lebih mudah memberikan laporan barang bekas kepada Junior Manager dan Inventory Warehouse Management Manager.

2. Rancangan sistem informasi pendataan barang bekas dengan menggunakan metode berorientasi objek dengan penggunaan diagram UML Dimana perancangan sistem yang dibuat dapat melakukan klasifikasi (pengkategorian) untuk menentukan jenis-jenis barang yang ada yaitu aktiva dibiayakan, persediaan, dan berbahaya dan beracun (sampah). Hal tersebut di buat agar dapat mempermudah Staff Warehouse untuk melakukan estimasi biaya lelang, jumlah barang yang akan dilelang dan untuk memberikan laporan barang bekas kepada pimpinan warehouse.

3. Sistem dibuat berdasarkan hasil diskusi dan juga wawancara dengan stake holder sehingga menghasilkan daftar kebutuhan fungsional yang telah dituliskan oleh peneliti dalam bentuk Tabel elisitasi. Kemudian kebutuhan fungsional tersebut di jadikan sebagai dasar dari rancangan sistem yang diusulkan oleh peneliti dalam bentuk sistem informasi pendataan barang habis pakai berbasis web. 


\section{DAFTAR PUSTAKA}

Aminudin. 2015. Cara Efektif Belajar Framework Laravel. Yogyakarta : Penerbit Lokomedia.

Aris, Donatus Agus Andriyanto, Yudha Surya Putra. 2016. Aplikasi Sistem Penjualan Perlengkapan Taekwondo Berbasis Online Pada Toko Sport Taekwondo Mawar Hitam Kab. Tangerang. Tangerang:Perguruan Tinggi Raharja (Vol. 2 No. 1 - Februari 2016).

Athoillah Muhammad dan M.Isa Irawan. Perancangan Sistem Informasi Mobile Berbasis Android Untuk Kontrol Persediaan Barang Di Gudang. Jurnal Sains Dan Seni Pomits. Surabaya: Institut Teknologi Sepuluh Nopember (ITS) (Vol. 1, No. 1 2013).

Basuki Awan Pribadi. 2016. Konsep dan Implementasi Pemrograman Laravel 5. Yogyakarta: Penerbit Lokomedia.

Budiman Erwin, Sifrid Pangemanan, Steven Tangkuman. 2014. Analisis Perlakuan Akuntansi Aktiva Tetap pada PT. Hasjrat Multifinance Manado. Manado:Universitas Sam Ratulangi Manado. (Vol.2 No. 1, Maret 2014).

Cahyosatrio Dwi Aji, Moch Dzulkirom, Muhammad Saifi. 2014. Analisis Capital Budgeting Sebagai Salah Satu Metode Untuk Menilai Kelayakan Investasi Aktiva Tetap Mesin Dan Kendaraan (Studi Kasus Pada Perusahaan Malang Indah). Malang:Universitas Brawijaya (Vol.9 No.1, April 2014).

Dewanto Joko, Yetti Kusmira. 2014. Analisi dan Perancangan Sistem Informasi Pengolahan Data Barang Masuk dan Keluar Gudang Barang Jadi dan Logistik di PT SNFOOD. Jakarta: Universitas Esa Unggul. (Vol. 11, No.1 Januari 2014).

Dewi Christine, Kevin Hasudungan Brotosetyo Putro, Ramos Somya. 2016. Implementasi Sistem Klaim Asuransi Kendaraan Bermotor di PT. IBS Insurance Broking Service Jakarta Berbasis Mobile. CCIT. Tangerang:Perguruan Tinggi Raharja. (Vol. 9 No. 2 - Januari 2016).

Dzulhaq M.iqbal, Rahmat Tullah, Putra Satia Nugraha. 2017. Sistem Informasi Akademik Sekolah Berbasis Kurikulum 2013. Jurnal Sisfotek Global. Tangerang:STMIK Bina Sarana Global. (Vol.7 No.1 Maret 2017).

Haerudin, Ruli Suprianti, Abdul Hakim. 2013. Perancangan Sistem Informasi Perpustakaan Berbasis WEB pada Madrasah Aliyah Negeri Balaraja Kabupaten Tangerang. Jurnal CCIT. Tangerang:Perguruan Tinggi Raharja. (Vol.7 No. 1 September 2013).

Hasanah Rizkha Surya, Kusni Hidayati, Widya Susanti. 2016. Penerapan Metode Depresiasi Aktiva Tetap Dan Pengaruhnya Terhadap Laporan Keuangan Pada PT. Prima Jaya Persada Nusantara Surabaya. Surabaya : Universitas Bhayangkara Surabaya.

Hidayatullah Priyanto, Jauhari Khairul Kawistara. 2014. Pemrograman WEB. Bandung:Informatika Bandung. 
Imeokparia Lawrence. 2013. Inventory Management System and Performance of Food and Beverages Companies in Nigeria. IOSR Journal of Mathematic. Nigeria: University Mowe Ogun State Nigeria. (Vol. 6, Issue 1 April 2013).

Indah Ika Nur. 2013. Pembuatan Sistem Informasi Penjualan Pada Toko Sehat Jaya Elektronik Pacitan. Indonesian Jurnal On Computer Science-Speed (IJCSS). Surakarta:Universitas Negeri Surakarta. (Vol. 10 No. 2 - Mei 2013).

Irwansyah Edi, dan Jurike V. Moniaga. 2014. Pengantar Teknologi Informasi. Yogyakarta:Deepublish.

Juliana Heldy, Naniek Utami Handayani. 2016. Peningkatan Kapasitas Gudang Dengan Perancangan layout Menggunakan Metode Class -Based Storage. Jurnal Teknik Industri. Semarang: Universitas Diponegoro. (Vol. XI, No. 2, Mei 2016).

Lestari Arinda, John Roni Coyanda, Dasrial. 2015. Sistem Informasi Pelelangan Barang Secara Online pada PT. Pegadaian (Persero) Unit Pelayanan Cabang Pasar 26 Ilir Palembang. Jurnal Informatika Global. Palembang:Universitas Indo Global Mandiri. (Vol 6 No 1 - Desember 2015)

Magureanu Gabriela, Mandalin Gavrilescu dan Pescaru. 2013. Validation of static properties in unified modeling language models for cyber physical systems. Journal of Zhejiang University-Science C (computers \& Electronics). Romania: University of Timisoara. (14(5):332-346 - Maret 2013).

Mairuhu Samuel, Jantje J. Tinangon. 2014. Analisis Penerapan Metode Penyusutan Aktiva Tetap Dan Implikasinya Terhadap Laba Perusahaan Pada Perum Bulog Divre Sulut Dan Gorontalo. Manado:Universitas Sam Ratulangi Manado. (Vol.2 No.4 Desember 2014). 